\title{
Cuidado em saúde mental por meio de grupos terapêuticos de um hospital-dia: perspectivas dos trabalhadores de saúde"
}

Daisyanne Soares Benevides ${ }^{1}$ Antonio Germane Alves Pinto ${ }^{2}$ Cinthia Mendonça Cavalcante ${ }^{3}$

Maria Salete Bessa Jorge ${ }^{4}$

BENEVIDES, D.S. et al. Mental healthcare through therapeutic groups in a day hospital: the healthcare workers' point of view. Interface - Comunic., Saude, Educ., v.14, n.32, p.12738, jan./mar. 2010.

The objective of this study was to understand the practices and knowledge involved in group therapeutic approaches and their linkages with mental healthcare provision in a day hospital $(\mathrm{DH})$ in the city of Fortaleza, Ceará. This was a descriptive study with a qualitative approach. To gather data, semi-structured interviews were conducted by 14 professionals at the $\mathrm{DH}$, along with systematic observation of practices. In the critical reflective analysis, convergences and divergences in the professionals' discourse and field observations were sought. From this analysis, the group therapeutic practices developed at the $\mathrm{DH}$ were important for individuals' psychosocial rehabilitation. The team at the $\mathrm{DH}$ used care provision devices such as linkage, reception, creation of coresponsibility and autonomy. In caring for subjects, the team sought to understand their complexity and subjectivity. The care provision at the $\mathrm{DH}$ included participation by patients' families, and this permeated the entire therapeutic project.

Keywords: Day hospital. Mental health. Therapeutic group and care.
O objetivo deste trabalho foi compreender as práticas e os saberes envolvidos nas abordagens terapêuticas grupais e suas articulações com a produção do cuidado em saúde mental em um Hospital-Dia (HD) da cidade de Fortaleza-CE, por meio de pesquisa descritiva, com abordagem qualitativa. Para coleta de dados, realizou-se entrevista semiestruturada com 14 profissionais do HD, além da observação sistemática das práticas. $\mathrm{Na}$ análise crítica e reflexiva, buscaram-se convergências e divergências entre as falas dos profissionais e as observações no campo. De acordo com essa análise, as práticas terapêuticas grupais desenvolvidas no HD são importantes para a reabilitação psicossocial dos sujeitos e a equipe do HD utiliza dispositivos para a produção do cuidado, tais como: vínculo, acolhimento, corresponsabilização e autonomia. Ao cuidar do sujeito, a equipe procura entender sua complexidade e subjetividade. A produção do cuidado no HD inclui a participação da família do paciente e perpassa todo o projeto terapêutico.

Palavras-chave: Hospital-dia. Saúde mental. Grupo terapêutico e cuidado.

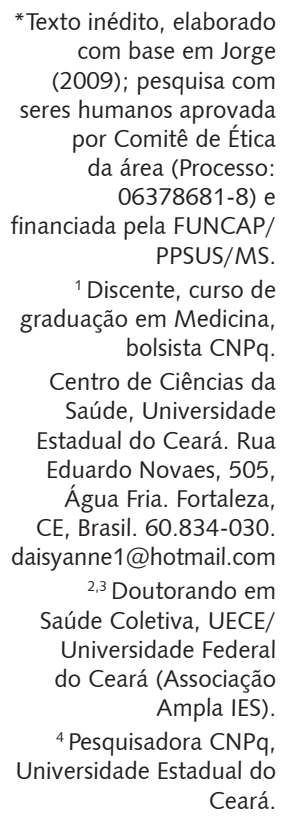

*Texto inédito, elaborado com base em Jorge (2009); pesquisa com seres humanos aprovada por Comitê de Ética da área (Processo: 06378681-8) financiada pela FUNCAP/ PPSUS/MS

${ }^{1}$ Discente, curso de graduação em Medicina, bolsista CNPq

Centro de Ciências da Saúde, Universidade Estadual do Ceará. Rua Eduardo Novaes, 505, Água Fria. Fortaleza,

CE, Brasil. 60.834-030. daisyanne1@hotmail.com 2,3 Doutorando em Saúde Coletiva, UECE/ Universidade Federal do Ceará (Associação Ampla IES).

${ }^{4}$ Pesquisadora CNPq, Universidade Estadual do Ceará. 


\section{Introdução}

A atenção psicossocial direciona suas ações para a construção da cidadania, da autoestima e da interação do indivíduo com a sociedade. Nesta realidade, a reprodução social do sujeito em sofrimento psíquico perpassa a prática clínica e constitui um processo complexo. Assim, a prática clínica exercida na rede de atendimento requer instrumentos e estratégias para a efetivação de ações resolutivas. Nesse sentido, o desenvolvimento das abordagens terapêuticas no trabalho em saúde mental ocorre com vistas a melhorar o enfrentamento do transtorno psíquico (Amarante, 2007; Oliveira, Ataíde, Silva, 2004).

No Brasil, a prática de psicoterapia de grupo expandiu-se a partir do contexto da Reforma Psiquiátrica (Guanaes, Japur, 2001). Nesse contexto da desinstitucionalização, fez-se necessária a elaboração de novas abordagens terapêuticas que vislumbrassem a dimensão psicossocial do sofrimento e que levassem em consideração a subjetividade humana e a inclusão social, por meio da cidadania e da autonomia.

As novas abordagens constituem uma tentativa de compreender a doença mental de forma diferente, com ênfase na pessoa doente, na sua forma de vida, na realidade em que está inserida, e não na doença em si, diferentemente da prática constante nos últimos séculos (Amarante, 1996).

O grupo terapêutico potencializa as trocas dialógicas, o compartilhamento de experiências e a melhoria na adaptação ao modo de vida individual e coletivo. Para Cardoso e Seminotti (2006), o grupo é entendido pelos usuários como um lugar onde ocorre o debate sobre a necessidade de ajuda de todos. No desenvolvimento das atividades, os participantes fazem questionamentos sobre as alternativas de apoio e suporte emocional.

Contudo, alguns pacientes sentem dificuldade de interagir com o grupo, sobretudo por estarem diante de pessoas desconhecidas; apesar desse entrave, acham importante ouvir as experiências de vida dos colegas e aprender com os relatos (Peluso, Baruzzi, Blay, 2001).

Nessa estratégia de promoção do sujeito, estão incluídos os grupos terapêuticos. Ao tomarem parte desses grupos, os participantes relatam: melhora nas relações sociais, nos níveis de conhecimento sobre questões discutidas no grupo, na capacidade para lidar com situações inerentes ao transtorno sofrido, na confiança, além de alívio emocional (Guanaes, Japur, 2001; Contel, Villas-Boas, 1999).

Quando o paciente tem melhor compreensão da própria subjetividade, sua autoimagem pode ser remodelada. Desse modo, ele pode obter uma melhor relação consigo mesmo e, consequentemente, com a sociedade (Bechelli, Santos, 2006).

Do tratamento do sujeito fazem parte a consulta e a medicação. Além disso, ele precisa de espaços de convivência e criação onde possa expressar opiniões e escolhas. No grupo terapêutico, ele desenvolve laços de cuidado consigo mesmo e compartilha experiências com os demais (Mendonça, 2005).

Como mostra a literatura, a terapia psicossocial proporciona diversas formas de atividades, como as atividades motoras (esportes, trabalhos em madeira e couro), sociais (comemorações festivas, teatros e cinema) e autoexpressivas (atividades espontâneas como cerâmica, pintura e dança). Essas práticas ampliam a habilidade e a autonomia do sujeito ao permitirem a ele o desenvolvimento do potencial da criatividade e da expressão. Os espaços terapêuticos trabalham as relações interpessoais dos sujeitos aliadas ao reconhecimento e ao respeito das diversidades existentes no grupo. São espaços de comunicação e integração (Valladares et al., 2003).

No tratamento do portador de transtorno mental também é fundamental o apoio da família e da comunidade. Ao compreenderem a terapêutica e colaborarem com seu desenvolvimento, essas pessoas estarão mais aptas a cuidar, de forma adequada, do sujeito (Jorge et al., 2006).

Diante do contexto, delineou-se como objetivo operacional da pesquisa: compreender práticas e saberes envolvidos nas abordagens terapêuticas grupais e sua articulação com a produção do cuidado em saúde mental em um Hospital-Dia localizado na cidade de Fortaleza-CE. 


\section{Metodologia}

\section{Natureza da pesquisa}

Trata-se de pesquisa crítica e reflexiva, com abordagem qualitativa, por coincidir com a configuração contextual do objeto de estudo assim como por constituir uma discussão aprofundada sobre a realidade social a partir de um referencial teórico-ideológico, no caso, a Reforma Psiquiátrica brasileira e a atenção psicossocial.

Para Minayo (2008, p.57), a pesquisa qualitativa

[...] além de permitir desvelar processos sociais ainda pouco conhecidos referentes a grupos particulares, propicia a construção de novas abordagens, revisão e criação de novos conceitos e categorias durante a investigação. Caracteriza-se pela empiria e pela sistematização progressiva de conhecimento até a compreensão lógica interna do grupo ou do processo em estudo.

A pesquisa qualitativa aplica-se a grupos e seguimentos delimitados, em busca da compreensão das relações sociais existentes, levando-se em consideração o subjetivo e o simbólico difundidos no meio social. Nesse tipo de pesquisa, a objetivação assume decisiva importância para ajudar o pesquisador a ter uma visão crítica de seu trabalho, além de proporcionar um meio mais eficiente para atingir a finalidade do seu estudo (Minayo, 2008).

\section{Campo empírico da pesquisa}

Segundo mencionado, o campo da pesquisa foi o Hospital-Dia localizado nas proximidades de um hospital psiquiátrico na cidade de Fortaleza-CE. O HD constitui um anexo do Hospital de Saúde Mental de Messejana (HSMM). É um serviço substitutivo intermediário entre a internação no hospital psiquiátrico e a prática ambulatorial, cujo objetivo é atender os sujeitos com transtornos mentais, com vistas à melhor relação sociofamiliar, no intuito de reduzir o número de internações e favorecer a abordagem psicossocial. Como um serviço de atenção terciária que desenvolve ações de cuidado intensivo desempenhadas por equipe multidisciplinar, tem como principais atividades as seguintes: realização de triagem, de avaliação, de diagnóstico e de plano terapêutico; atendimentos individuais ao usuário e aos familiares; atendimento nuclear de família; grupos psicoterapêuticos, educativos, expressivos, sociofamiliar, de cidadania; visitas domiciliares e comunitárias; oficinas de terapia ocupacional; oficinas socioeducativas nas comunidades e atividades socioterápicas.

\section{Participantes da pesquisa}

Foram entrevistados 14 trabalhadores de saúde mental da instituição pesquisada, dentre eles: três médicos, uma psicóloga, uma enfermeira, uma socióloga, uma terapeuta ocupacional, uma assistente social, uma auxiliar de enfermagem, uma agente de administração, duas colaboradoras em saúde mental, uma jardineira, uma copeira. Dos entrevistados, a maioria $(92,85 \%)$ é do sexo feminino e a faixa etária dos trabalhadores estende-se de 23 a 68 anos. Também a maioria dos trabalhadores de nível superior possui especialização e/ou aperfeiçoamento e/ou extensão na área de saúde pública (88,88\%).

\section{Técnicas e instrumentos de coleta das informações}

Para a coleta de dados qualitativos, foram utilizadas duas técnicas: a entrevista semiestruturada e a observação sistemática das práticas no Hospital-Dia. A entrevista semiestruturada baseia-se na comunicação verbal, que articula perguntas abertas e fechadas, pois, desse modo, o entrevistado tem mais liberdade para discorrer sobre as questões abordadas. É uma técnica na qual a subjetividade pode 
ser bem analisada (Minayo, 2008). Quanto à observação sistemática, foi orientada pelo mesmo roteiro da entrevista, para possibilitar o confronto com os dados apreendidos entre a representação (fala/ depoimento) e a prática concreta no serviço de saúde mental. Tais observações ocorreram no momento de interação entre trabalhadores de saúde do HD e os usuários, nos diversos locais de atendimento terapêutico, no consultório, na área externa, no refeitório ou nas salas de grupo.

\section{Análise e interpretação}

$\mathrm{Na}$ análise do material empírico das entrevistas e das observações, para o melhor entendimento das questões deste estudo, tomou-se como base Minayo (2008), segundo a qual o objeto de análise é a práxis social. No primeiro contato com os dados brutos, realizou-se a transcrição do material gravado em audiodigital. Houve leitura do material e criação de núcleos de sentido. Em seguida, esses núcleos de sentido foram agrupados em categorias e procedeu-se à organização dos dados contemplados nas entrevistas e nas observações, com o intuito de buscar convergências e divergências extraídas entre as falas dos participantes e entre estas e as observações. Surgiram, então, as seguintes categorias: Da Clínica Oficial à Clínica Psicossocial e Produção do Cuidado e o Trabalho em Equipe. A seguir, fez-se a interpretação à luz da literatura pertinente.

Essa análise foi ilustrada com os discursos dos participantes da investigação. As ilustrações dispõem à reflexão que sintetiza o grupo de convergência, divergência e complementaridade de cada discurso dos sujeitos pesquisados, com a finalidade de ampliar a compreensão do fenômeno.

\section{Questões éticas}

De acordo com o exigido, o projeto foi submetido à análise do Comitê de Ética em Pesquisa (CEP) da Universidade Estadual do Ceará (UECE). Após o parecer favorável do CEP/UECE, iniciou-se a pesquisa de campo. Ainda como exigido, a coleta de dados foi autorizada por escrito pela instituição pesquisada. Para a realização de cada técnica de coleta, o participante foi informado sobre os procedimentos do estudo e teve acesso ao termo de consentimento livre e esclarecido, em atendimento aos princípios éticos, conforme Resolução 196/96 do Conselho Nacional de Saúde (Brasil, 2000).

Garantiu-se que a pesquisa não traria prejuízo na qualidade e condição de vida e trabalho dos participantes, salientando que as informações seriam sigilosas e que não haveria divulgação personalizada.

Foi esclarecido que os dados e as informações coletadas seriam utilizados para compor os resultados da investigação, possibilitando o benefício de ampliar a visão dos gestores de saúde, com a finalidade de criar políticas públicas que melhorassem a qualidade dos serviços.

\section{Resultados}

\section{Da clínica oficial à psicossocial}

No HD, os profissionais organizam grupos terapêuticos dentro da área na qual atuam. Por exemplo, a socióloga realiza um grupo com os usuários abordando o resgate da cidadania dessas pessoas. Os participantes se dispõem numa roda na perspectiva de evitar uma relação de hierarquia entre profissional e usuários e os temas escolhidos giram em torno da frase "o que é cidadania?", procurando-se enfatizar a realidade local. Em outro momento, há distribuição de revistas, cartazes, cola e pincel para que o grupo possa, por meio da arte, discutir sobre os direitos e deveres do cidadão.

Nesse processo, a psicóloga desempenha um trabalho de musicoterapia ativa, para o qual ela leva vários instrumentos que são tocados pelos usuários e funcionam como um intermediário na comunicação. Funcionam como outras formas de linguagem, diferentes da linguagem verbal. Ao final de 
cada reunião, eles pedem uma música e, depois de tocada, a psicóloga pergunta o motivo da escolha, tentando compreender as vivências de cada usuário e permeando o universo de cada um deles.

"Quando eu vou encerrar um grupo, cada um escolhe uma música, eu peço 'você escolhe alguma música que lhe dê segurança, que você se sinta bem, que lhe identifique, que fale um pouco de você'. [...] Então eu procuro ver o universo deles, a vivência deles". (Trabalhador 14)

Tal como a psicóloga, a enfermeira também possui sua estratégia de trabalho. Para isto, estrutura um grupo educativo, com ênfase em esclarecimentos sobre doenças e sobre o cuidado com a higienização. A exemplo destas duas profissionais, a fisioterapeuta começou a formar um grupo envolvendo atividades físicas, trabalhando o relaxamento muscular. Mas como ela é coordenadora do $H D$, suas obrigações demandam muito tempo, e esse grupo não é tão ativo.

Outra profissional atuante é a psiquiatra. Ela desenvolve um grupo de psicoeducação, no qual discorre sobre o processo saúde/doença, conscientizando os usuários sobre seus transtornos e esclarecendo dúvidas pertinentes.

“[...] eles querem entender um pouco da doença deles. [...] o que é uma alucinação, o que é um delírio, e eles perguntam e eu vou respondendo de acordo com o que eles querem saber. [...] eles trocam informações e depois o coordenador e os observadores vão falar algo do que surgiu naquele momento". (Trabalhador 4)

A educação em saúde pode efetivar mudanças do comportamento e da subjetividade de agrupamentos, ao ampliar a intervenção das pessoas sobre sua própria realidade, modificando seu contexto de vida (Campos, 2007).

Com esta finalidade, o psicólogo tem um grupo de teatro, no qual os usuários escolhem o que querem dramatizar e fazem a sinopse. Nesse grupo, uma interação muito forte é percebida entre os participantes. Mesmo pacientes que já receberam alta hospitalar, pedem autorização para permanecer no grupo.

“[...] ele [psicólogo] tá fazendo um teatro com eles [usuários] e eles adoram. Então tem aqueles pacientes que já saíram daqui e que pedem pra retornar pra ficar no teatro. É um momento que eles interagem mesmo". (Trabalhador 1)

Peluso, Baruzzi e Blay (2001) discorrem sobre o desfecho clínico da psicoterapia em que os pacientes relatam a sensação de alívio, clarificação, modificação de alguns padrões de comportamento e redução do isolamento social. A trajetória terapêutica desses pacientes destaca-se pela elevada frequência e pela continuidade à psicoterapia, até mesmo nos que não perceberam mudanças com a intervenção.

Há também grupos que envolvem mais de um profissional. No grupo sociofamiliar, psicólogo, médico, assistente social e enfermeira participam desse momento e contribuem para um melhor relacionamento dos familiares com os usuários. Nesse grupo, os familiares são estimulados a falar das principais dificuldades enfrentadas na produção do cuidado aos pacientes. Quando ocorre diálogo entre familiares, há a percepção da possibilidade de ajuda mútua em virtude de problemas semelhantes. O sentimento de não estarem sós nessa luta por uma melhor qualidade de vida dentro da família transcende as dificuldades impostas e fortalece o cuidado ao sujeito.

"O acolhimento é bom: eles chegam, são acolhidos por toda a equipe, que é a reunião de família. A família é acolhida pela equipe nas necessidades do paciente, qualquer necessidade que a família tenha, [...] tem todo um esclarecimento [...], eles são acolhidos de uma forma bem terapêutica". (Trabalhador 9) 
“E o projeto do serviço social é sempre a questão da inclusão da família no processo de tratamento". (Trabalhador 13)

Trabalhar em equipe não significa abdicar das particularidades de cada profissão, mas utilizar a cogestão para assegurar saúde de qualidade para quem necessita (Campos, 2007).

De modo geral, o grupo terapêutico possibilita o compartilhamento de experiências entre os participantes, propicia escuta, orientação e construção de projetos terapêuticos condizentes com as necessidades dos sujeitos. Ao mesmo tempo, a vivência em grupo favorece maior capacidade resolutiva, por possuir vários olhares direcionados para um problema em comum (Schrank, Olschowsky, 2008). Essa vivência enseja a construção de novas visões e sentidos capazes de proporcionar mudanças significativas na percepção de vida de seus integrantes (Guanaes, Japur, 2005).

Existe também o grupo de acolhimento, às segundas-feiras, cuja finalidade é escutar o usuário sobre seu final de semana; além do grupo de avaliação da semana, às sextas-feiras, no qual os usuários podem fazer uma reflexão sobre as atividades desenvolvidas durante a semana. Conforme se percebe, os usuários têm a possibilidade de questionarem sobre o tratamento que estão recebendo no HD:

“E na sexta eles têm um grupo de avaliação da semana [...] aí eles podem reclamar, reivindicar ou agradecer, seja o que for". (Trabalhador 2)

"Como foi o final de semana? Se eles passearam? Se eles se divertiram? Se eles tomaram banho? Se eles comeram bem? Tudo isso elas [trabalhadoras] perguntam. É um grupo muito bom, elas dão umas explicações muito boas. Eles gostam. Eles gostam muito". (Trabalhador 12)

O acolhimento desenvolvido pela equipe multidisciplinar compromete-se com a escuta do sujeito, empenha-se na resolução de seus problemas. Tem a finalidade de qualificar a relação entre equipe e usuário, com vistas à integralidade do atendimento ao sujeito. De acordo com determinados autores, a intensificação de práticas acolhedoras é um passo fundamental para se alcançar a efetivação da produção do cuidado, contribuindo para uma clínica mais humana e cidadã (Santos et al., 2007; Franco, Bueno, Merhy, 2006).

“[...] eles são acolhidos aqui e são muito bem tratados aqui". (Trabalhador 11)

Desse modo, pode-se chegar à integralidade, a se iniciar na organização do processo de trabalho, que envolve uma assistência desenvolvida pela interdisciplinaridade da equipe e conta com acolhimento e vínculo, além da responsabilização do cuidado (Franco, Magalhães Júnior, 2006).

Tal como outras iniciativas, as oficinas terapêuticas também são realizadas dentro de um contexto grupal. São atividades desenvolvidas pelos profissionais da terapia ocupacional e incluem: pintura, colagem, modelagem, trabalhos com sucata, papel reciclado e carpintaria.

Complementarmente, com o auxílio dos profissionais da nutrição, os usuários se reúnem para fazer saladas de frutas. Há também o cuidado com a horta, além de momentos de descontração, quando eles participam de bingos, jogos, assistem à televisão e ouvem músicas.

Pelas narrativas dos profissionais, percebe-se que as atividades terapêuticas grupais desenvolvidas no HD proporcionam um sentimento de prazer, de entusiasmo e de satisfação para os usuários. Ao se observarem as práticas, evidenciam-se a satisfação e a interação de alguns usuários; outros já não são tão ativos, mas dão sua contribuição na dinâmica grupal. Essas atividades desempenham um papel importantíssimo para a reabilitação do paciente.

“[...] eles adoram por sinal [...] todos eles gostam! Mas a música mexe muito com eles [...]. Então eles adoram, eles interagem, eles cantam, eles colocam as emoções pra fora, sabe? É uma coisa assim tão interessante [...] eu via assim uma interação, uma liberação, assim, um envolvimento". (Trabalhador 1) 
“[...] até mesmo final de semana que eles vão pra casa 'aí eu queria tanto que esse tivesse passado rápido pra vir pra cá'. Quer dizer, eles gostam daqui, eles gostam do ambiente". (Trabalhador 3)

Com relação às atividades individuais, nota-se a predominância de consultas com médicos e psicólogos para avaliar se o paciente está aderindo ao tratamento e se está se relacionando bem com a família. As entrevistas com os médicos ocorrem três vezes por semana e, caso haja necessidade, também são feitas visitas domiciliares.

No desempenho do seu trabalho, a equipe do HD está constantemente em busca do melhor para os pacientes. Mesmo diante de resultados satisfatórios na recuperação destes, a equipe do HD se reúne para discutir sobre as perspectivas de novas abordagens terapêuticas passíveis de proporcionar maior qualidade de vida aos usuários.

\section{Produção do cuidado e o trabalho em equipe}

Após receberem alta do HD, muitos usuários pedem para permanecer no serviço, motivados pela satisfação em participar dos grupos terapêuticos. Outra justificativa para isto pode ser a falta de assistência fora do HD. Como mostra a realidade, as necessidades de saúde não se limitam aos transtornos mentais: elas são bem maiores e envolvem questões financeiras, sociais e culturais. Dentro do HD, essas necessidades são amenizadas: há alimentação, interação com as outras pessoas, acolhimento, vínculo. Fora do HD, os usuários ainda enfrentam fome, desprezo e preconceito.

\section{“[...] muitas vezes eles querem até ser alienados pra poder receber o benefício que é a estratégia de sobrevivência". (Trabalhador 2)}

Neste sentido, as práticas, os procedimentos e as orientações da clínica oficial são insuficientes para abordar toda a variedade de dimensões que compõem as demandas e as necessidades de saúde das pessoas. Para ir além, por conseguinte, é essencial instrumentalizar-se de ações coletivas fortalecidas pela intersetorialidade e pela rede de referência e contrarreferência eficiente (Fracolli, Zoboli, 2004).

A equipe multidisciplinar do HD trabalha em sintonia. Nas reuniões semanais, toda ela discute sobre o projeto terapêutico de cada usuário e interfere no decorrer de todo o tratamento.

"[...] todos os profissionais daqui têm essa concepção de que eles, além do transtorno, eles são seres humanos que precisam da equipe, e a gente tem muita atenção, muito carinho [...] é uma equipe muito envolvida. A gente tem que estar preocupada com o bem-estar deles. [...] Assim eu acho tão envolvente esse trabalho daqui, eu acho tão bom, é uma coisa tão boa que às vezes a gente tem até pena de dizer um não porque eles sentem essa necessidade". (Trabalhador 1)

Inegavelmente, o trabalho em equipe traz novas possibilidades de atuação, sobretudo por contribuir para uma melhor qualidade do serviço, pois atua no planejamento de ações mais efetivas, estabelecendo prioridades na realização das práticas, além de intervenções mais criativas no processo de trabalho (Pinho, 2006).

Segundo Pinto (2008), o desenvolvimento do projeto terapêutico deve procurar respeitar a singularidade de cada sujeito. Produzir cuidado não é atuar de forma burocrática e mecanicista, e sim perceber que o caráter individual do sujeito tem importante relevância no dinamismo do cuidado.

Com vistas a ações integrais e efetivas, muitas vezes é preciso criatividade do profissional, além de uma boa comunicação tanto com o usuário, quanto com os demais profissionais da equipe. Um bom profissional deve saber que angústias não são padronizadas e que pessoas não são fragmentadas. Portanto, as práticas e os saberes de toda a equipe serão mais resolutivos do que a individualização do conhecimento (Ciuffo, Ribeiro, 2008). 
No projeto terapêutico, a responsabilidade cabe não apenas à equipe, mas também ao usuário e à família. Embora a família, às vezes, deseje a internação do paciente, a equipe do HD tenta dissuadi-la e conscientizá-la de sua importância no tratamento dentro de casa, no cuidado ao paciente. Como sujeitos do processo, os pacientes são esclarecidos sobre sua doença e têm autonomia para aderir ou não ao projeto terapêutico proposto.

“[...] a gente tenta conscientizar a família de que se o paciente não tem o apoio familiar, ele não vai ter uma resposta tão satisfatória. [...] Pra ele ser reintegrado na sociedade é uma coisa muito difícil. [...] a gente percebeu que a família queria se livrar do problema". (Trabalhador 1)

"[...] a gente procura saber, conversar, saber como foi o dia do paciente, se ele tomou a medicação realmente. [...] não só com o paciente, a gente também tenta conversar com a família". (Trabalhador 8)

Para que o paciente permaneça integrado ao serviço, ele precisa participar das atividades sugeridas no projeto terapêutico. Apesar disso, quando o paciente não está disposto a participar de todas as atividades, sua liberdade é respeitada.

Existe um vínculo muito forte entre os usuários e a equipe do HD. No Hospital-Dia eles são tratados como seres humanos dignos de respeito e atenção. Há uma interação entre os profissionais e os usuários, e os sentimentos de afeto são mútuos. A família também está envolvida e vinculada à produção do cuidado.

“[...] eles recebem alta e ficam voltando cá, ficam querendo ficar aqui. Abraçam a gente, conversam muito com a gente, todo dia eles querem um atendimento da gente porque se sentem bem". (Trabalhador 3)

"Aqui a gente tem um vínculo muito grande com o usuário e com a família. A gente tenta de todo jeito ajudar o paciente". (Trabalhador 7)

Para Campos (2007), o vínculo se constitui na troca entre a oferta do serviço de saúde dos trabalhadores e a demanda da resolução do sofrimento do usuário. É uma troca de afetos, na qual a equipe e o usuário precisam acreditar na resolubilidade do tratamento para que esse vínculo não se torne "paternalista". Deve-se estimular o usuário a também participar da resolução de seus problemas, ou seja, deve haver corresponsabilização no projeto terapêutico. Segundo o autor, "a prática de uma clínica com qualidade é o fortalecimento de vínculos entre paciente, famílias e comunidade com a equipe e com alguns profissionais específicos que Ihes sirvam de referência" (Campos, 2007, p.68).

O vínculo permite o compartilhamento de saberes e vivências entre equipe e usuário, ampliando as potencialidades dessas pessoas. Permite o desenvolvimento de corresponsabilização do projeto terapêutico, para que esse projeto não seja desenvolvido de forma única e absoluta pelo profissional, nem movido apenas pelas vontades e anseios dos usuários (Santos et al., 2008).

Como propõe a literatura, a adoção de práticas e processos voltados para a saúde mental requisita elementos da subjetividade e condição humana, e, para se obter um estado de equilíbrio sistêmico e psicológico, a corresponsabilização terapêutica e os momentos de escuta e diálogo entre o terapeuta e o paciente são necessários (Bechelli, Santos, 2006; Campos, 2006).

No HD, o acolhimento diário propicia à equipe multiprofissional manter-se a par do ocorrido com o paciente nos cenários extra-hospitalares. A família também é acolhida nas reuniões de grupo: dúvidas e angústias são ouvidas, esclarecimentos e confortos são prestados a essas pessoas.

Embora parcialmente, as atividades desenvolvidas no HD proporcionam resolubilidade aos problemas dos usuários, pois a maior interação desses sujeitos com as famílias, com a equipe e com a comunidade permite convivência social, elevação na autoestima e melhor qualidade de vida. No HD, esses usuários são tratados com respeito e com dignidade. Por meio do projeto terapêutico 
desenvolvido, há visível redução no número de internações, com menor dependência dos usuários aos serviços de saúde e, consequentemente, maior autonomia.

É visível, também, o envolvimento social e laboral de alguns usuários, que voltam a trabalhar, a ter maior liberdade e melhor relacionamento social. Outros não alcançam a plenitude desse retorno social, mas conseguem uma melhor relação com os familiares. Para essa melhoria na qualidade de vida, a família tem importância fundamental: ao entender a doença e lidar devidamente com ela, as chances de recuperação são bem maiores.

"[...] eles [usuários] falam que adoram o hospital, que aqui tem gente como eles. [...] o paciente se sente útil. O paciente tem contato com outros pacientes, tem contado com a equipe, tem aquela integralização com a família, reunião de grupo com a família também, e eu acho que isso aqui evita sim o número de novos internamentos. [...] a gente vê que aqui no hospital-dia o paciente já tem uma funcionalidade melhor. Eu acho importantíssimo". (Trabalhador 5)

"[...] a gente vê que em parte o diferencial do hospital é que tem essas outras atividades de até (re) socialização mesmo". (Trabalhador 6)

"[...] quando sai do internamento que vem pra cá, se sente melhor ainda, porque ele não se sente preso. [...] além de ele ter liberdade, ter liberdade de tudo, ter os passeios dele, ter essas atividades, ter bingo, essas coisas assim, ele se sente melhor, se sente bem, se sente acolhido e se sente como uma pessoa mesmo". (Trabalhador 11)

Pelos serviços prestados, o HD recebe elogios, mas os profissionais questionam sobre os motivos desses elogios:

"A gente recebe elogios, mas aí tem que ver porque foi: será que é porque tá dando um alívio à família durante esse período? [...] Então essa história da resolutividade é muito difícil de falar". (Trabalhador 2)

De modo geral, as famílias não podem acompanhar rotineiramente as atividades do $\mathrm{HD}$, fato que compromete o projeto terapêutico. Além disso, o processo de alta hospitalar administrativa, que obedece às normas institucionais, dificulta a recuperação daqueles pacientes com problemas mais graves, que demandam mais tempo de recuperação. Alguns usuários não têm acesso ao projeto terapêutico adequado ou não participam conforme devido. Desse modo, retornam ao hospital psiquiátrico.

“[...] muitos se recuperam, mas muitos a gente chega no pavilhão [do hospital psiquiátrico HSMM] e já tá de volta. É uma tristeza, mas é verdade". (Trabalhador 10)

Diante desta situação, salienta-se: a questão social é muito complexa, e a resolubilidade não depende só do HD. Apesar de os profissionais se esforçarem com vistas ao resgate da cidadania do usuário, a contribuição da família e da comunidade neste processo é essencial.

Ressalta-se, também, o preconceito social sofrido pelos usuários, o qual vai de encontro às propostas reabilitadoras dos serviços de saúde mental, interessadas em proporcionar espaços de convivência salutar, onde a integração e o envolvimento se façam presentes. Esse preconceito compromete a resolubilidade (Pinto, 2008).

No HD, a produção do cuidado em saúde mental perpassa todo o processo terapêutico do indivíduo. Ao cuidar do sujeito, deve-se levar em consideração sua autonomia, seus valores e sua subjetividade. Com o trabalho em equipe (envolvendo trabalhador, usuário e família), percebe-se uma integração na busca de melhorias de vida para esses sujeitos. 
Como observado, os espaços terapêuticos possibilitados pela expansão da rede de saúde mental promovem a aplicação das atividades interdisciplinares com o propósito direto de favorecer a reabilitação psicossocial. O HD está inserido nessa perspectiva e tenta oferecer um cuidado integral ao sujeito mediante participação da equipe e da família no projeto terapêutico.

Devido à organização administrativa dos serviços de saúde mental no município de Fortaleza-CE, o HD está sob gestão estadual, enquanto a rede de atenção à saúde mental municipal mantém o funcionamento dos Centros de Atenção Psicossocial (CAPS), unidades de internação em hospital geral e serviços residenciais terapêuticos. Tal realidade dificulta algumas estratégias de interlocução entre estes dispositivos institucionais.

A despeito dos avanços, o HD ainda está desprovido da diretriz referente à perspectiva territorial do cuidado (Brasil, 2003), do ponto de vista sócio-histórico, representa um espaço de transformação de práticas e um dispositivo para (re) construção da rede de atenção psicossocial, desde que as relações entre os diversos serviços sejam continuamente efetivadas no Sistema Único de Saúde (SUS).

\section{Considerações finais}

Segundo revelou a análise das entrevistas e das observações no campo, as práticas terapêuticas grupais desenvolvidas no HD são importantes para a reabilitação psicossocial, e a equipe do HD utiliza dispositivos para a produção do cuidado, tais como: vínculo, acolhimento, corresponsabilização e autonomia.

Ao cuidar do paciente, a equipe busca entender sua complexidade e subjetividade. Trabalha em sintonia e procura ter uma visão integral de cada caso. A produção do cuidado no HD inclui a participação da família do paciente e perpassa todo o projeto terapêutico.

Portanto, o cuidado produzido pela relação entre equipe e usuário não se restringe à administração de psicofármacos nem à realização de psicoterapias; vai além e constrói novas possibilidades de vida.

Diante dos resultados, enfatiza-se o seguinte: no presente trabalho, abordou-se a produção do cuidado por meio de grupos terapêuticos em apenas um Hospital-Dia. Assim, não se podem generalizar as abordagens terapêuticas realizadas nesse serviço para os demais serviços da rede de Fortaleza-CE. Além disso, como as entrevistas foram direcionadas somente aos trabalhadores de saúde mental, recomenda-se desenvolver outros estudos com usuários e familiares para confronto dos resultados de análise.

A utilização das terapias grupais na abordagem aos usuários possibilita a atuação interdisciplinar condizente com a prática clínica humana, equânime e resolutiva. Diante desta justificativa, o trabalho com grupos terapêuticos deve ganhar espaço nos serviços e instituições da rede de atenção à saúde, pois se trata de uma ação relevante no planejamento de intervenções clínicas, já que apresenta resultados positivos no acompanhamento de diversos agravos e doenças.

Muitos limites ainda devem ser superados no processo de transformação desse cenário. Para haver mudança, é essencial a participação e a mobilização de todos na construção de novos espaços, estratégias e soluções. Mas, inegavelmente, o crescimento teórico e a intensificação da habilidade prática proporcionam aos profissionais uma chance de ampliarem a relação com os usuários pelos dispositivos da produção do cuidado. 


\section{Colaboradores}

Os autores trabalharam juntos em todas as etapas de produção do manuscrito.

\section{Referências}

AMARANTE, P. Saúde mental e atenção psicossocial. Rio de Janeiro: Fiocruz, 2007.

O homem e a serpente: outras histórias para a loucura e a psiquiatria. Rio de Janeiro: Fiocruz, 1996.

BECHELLI, L.P.C.; SANTOS, M.A. Transferência e psicoterapia de grupo. Rev. Latino-am. Enferm., V.14, n.1, p.110-7, 2006.

BRASIL. Ministério da Saúde. Secretaria de Atenção à Saúde. Departamento de Ações Programáticas Estratégicas. Departamento de Atenção Básica. Coordenação Geral de Saúde Mental. Coordenação de Gestão da Atenção Básica. Saúde mental e a atenção básica: o vínculo e o diálogo necessários. Brasília: MS, 2003.

BRASIL. Ministério da Saúde. Secretaria de Atenção à Saúde. Departamento de Ações Programáticas Estratégicas. Departamento de Atenção Básica. Coordenação Geral de Saúde Mental. Coordenação de Gestão da Atenção Básica. Normas para pesquisa envolvendo seres humanos (Res. CNS 196/96 e outras). Brasília: Conselho Nacional de Saúde, Comissão Nacional de Ética em Pesquisa - CONEP, 2000. (Série Cadernos Técnicos).

CAMPOS, G.W.S. Saúde paidéia. São Paulo: Hucitec, 2007.

CAMPOS, R.O. A promoção à saúde e a clínica: o dilema "promocionista". In: CASTRO, A.; MALO, M. (Orgs.). SUS: ressignificando a promoção da saúde. São Paulo: Hucitec/ OPAS, 2006. p.62-74.

CARDOSO, C.; SEMINOTTI, N. O grupo psicoterapêutico no Caps. Cienc. Saude Colet., v.11, n.3, p.775-83, 2006.

CIUFFO, R.S.; RIBEIRO, V.M.B. Sistema Único de Saúde e a formação dos médicos: um diálogo possível?. Interface - Comunic., Saude, Educ., v.12, n.24, p.125-40, 2008.

CONTEL, J.O.B.; VILLAS-BOAS, M.A. Psicoterapia de grupo de apoio multifamiliar (PGA) em hospital-dia (HD) psiquiátrico. Rev. Bras. Psiquiatr., v.21, n.4, p.225-30, 1999.

FRACOLLI, L.A.; ZOBOLI, E.L.C.P. Descrição e análise do acolhimento: uma contribuição para o programa de saúde da família. Rev. Esc. Enferm. USP., v.2, n.38, p.143-51, 2004.

FRANCO, T.B.; BUENO, W.S.; MERHY, E.E. O acolhimento e os processos de trabalho em saúde: o caso em Betim (MG). In: MERHY, E.E. et al. (Orgs.). O trabalho em saúde: olhando e experienciando o SUS no cotidiano. São Paulo: Hucitec, 2006. p.37-54.

FRANCO, T.B.; MAGALHÃES JÚNIOR, H.M. Integralidade na assistência à saúde: a organização das linhas de cuidado. In: MERHY, E.E. et al. (Orgs.). O trabalho em saúde: olhando e experienciando o SUS no cotidiano. São Paulo: Hucitec, 2006. p.125-32.

GUANAES, C.; JAPUR, M. Sentidos de doença mental em um grupo terapêutico e suas implicações. Psicol.: Teor. Pesqui., v.21, n.2, p.227-35, 2005.

Grupo de apoio com pacientes psiquiátricos ambulatoriais em contexto institucional: análise do manejo terapêutico. Psicol. Reflex. Crit., v.14, n.1, p.191-99, 2001.

JORGE, M.S.B. Práticas de abordagens terapêuticas grupais dos trabalhadores de saúde na produção do cuidado em saúde mental, Fortaleza/CE. Relatório final da pesquisa. Fortaleza: GRUPSFE-UECE, 2009.

JORGE, M.S.B. et al. Reabilitação psicossocial: visão da equipe de saúde mental. Rev. Bras. Enferm., v.59, n.6, p.734-9, 2006. 
MENDONÇA, T.C.P. As oficinas na saúde mental: relato de uma experiência na internação. Psicol. Cienc. Prof., v.25, n.4, p.626-35, 2005.

MINAYO, M.C.S. O desafio do conhecimento: pesquisa qualitativa em saúde. São Paulo: Hucitec, 2008.

OLIVEIRA, A.G.B.; ATAIDE, I.F.C.; SILVA, M.A. A invisibilidade dos problemas de saúde mental na atenção primária: o trabalho da enfermeira construindo caminhos junto às equipes de saúde da família. Texto Contexto Enferm., v.13, n.4, p.618-24, 2004.

PELUSO, É.T.P.; BARUZZI, M.; BLAY, S.L. A experiência de usuários do serviço público em psicoterapia de grupo: estudo qualitativo. Rev. Saude Publica, v.35, n.4, p.341-8, 2001

PINHO, M.C. Trabalho em equipe de saúde: limites e possibilidades de atuação eficaz. Cienc. Cognição, v.8, p.68-87, 2006.

PINTO, A.G.A. Produção do cuidado em saúde mental: significados e sentidos da prática clínica em centro de atenção psicossocial. 2008. Dissertação (Mestrado) - Centro de Ciências da Saúde, Universidade Estadual do Ceará, Fortaleza. 2008.

SANTOS, A. M. et al. Vínculo e autonomia na prática de saúde bucal no Programa Saúde da Família. Rev. Saude Publica, v.42, n.3, p.464-70, 2008.

Linhas de tensões no processo de acolhimento das equipes de saúde bucal do Programa Saúde da Família: o caso de Alagoinhas, Bahia, Brasil. Cad. Saude Publica, v.23, n.1, p.75-85, 2007.

SCHRANK, G.; OLSCHOWSKY, A. O Centro de Atenção Psicossocial e as estratégias para inserção da família. Rev. Esc. Enferm. USP, v.42, n.1, p.127-34, 2008.

VALLADARES, A.C.A. et al. Reabilitação psicossocial através das oficinas terapêuticas e/ou cooperativas sociais. Rev. Eletron. Enferm., v.5, n.1, p.4-9, 2003.

BENEVIDES, D.S. et al. Cuidado en salud mental por medio de grupos terapéuticos de un hospital-día: perspectivas de los trabajadores de salud. Interface - Comunic., Saude, Educ., v.14, n.32, p.127-38, jan./mar. 2010.

El objetivo de este trabajo ha sido comprender las prácticas y los saberes comprendidos en los planteamientos terapéuticos grupales y sus articulaciones con la producción del cuidado en salud mental en un Hospital-Día (HD) de la ciudad de Fortaleza, Ceará, Brasil, por medio de investigación descriptiva con planteamiento cualitativo. Para la colecta de datos se ha realizado entrevista semi-estructurada con 14 profesionales del HD, además de la observación sistemática de las prácticas. En el análisis crítico y reflexivo se han buscado convergencias y divergencias entre las manifestaciones de los profesionales y las observaciones en campo. De acuerdo con este análisis las prácticas terapéuticas grupales desarrolladas en el HD son importantes para la re-habilitación psico-social de los sujetos; y el equipo del HD utiliza dispositivos para la producción del cuidado tales como vínculo, acogida, co-responsabilización y autonomía. Al cuidar del sujeto, el equipo trata de entender su complejidad y subjetividad. La producción del cuidado en el HD incluye la participación de la familia del paciente y adelanta todo el proyecto terapéutico.

Palabras clave: Hospital-día. Salud mental. Grupo terapéutico y cuidado.

Recebido em 26/03/2009. Aprovado em 10/08/2009. 